\title{
104. Measurement of vibrations of a wing
}

\author{
V. Maskeliūnas ${ }^{1}$, R. Maskeliūnas ${ }^{2}$, P. Paškevičius ${ }^{3}$, L. Ragulskis ${ }^{4}$ \\ ${ }^{1,2}$ Vilnius Gediminas Technical University, Vilnius, Lithuania \\ ${ }^{3}$ Kaunas University of Technology, Kaunas, Lithuania \\ ${ }^{4}$ Vytautas Magnus University, Kaunas, Lithuania \\ ${ }^{2}$ Corresponding author \\ E-mail: ${ }^{1}$ vytautas.maskeliunas@stud.vgtu.lt, ${ }^{2}$ rimas.maskeliunas@vgtu.lt, ${ }^{3}$ info@vaivorairko.lt, \\ ${ }^{4}$ l.ragulskis@if.vdu.lt
}

Received 1 September 2016; received in revised form 20 September 2016; accepted 23 September 2016

DOI http://dx.doi.org/10.21595/jme.2016.17772

\begin{abstract}
In the paper vibrations of a wing are investigated experimentally by using the method of time averaged projection moiré. Experimental setup is developed and the results obtained by using the experimental procedure are analyzed. Interpretation of projection moiré images on a shallow surface is more complicated than on a plane surface. For this purpose, a special simplified two-dimensional numerical model is developed and used in hybrid experimental - numerical procedures of investigation of vibrations of a wing.
\end{abstract}

Keywords: wing, elastic structure, vibrations, time averaged moiré, projection moiré, experimental setup, experimental results, hybrid experimental - numerical procedure.

\section{Introduction}

In the paper vibrations of a wing are investigated experimentally by using the method of time averaged projection moiré. Experimental setup is developed and the results obtained by using the experimental procedure are analyzed.

Interpretation of projection moiré images on a shallow surface is more complicated than on a plane surface. For this purpose, a special simplified two-dimensional numerical model is developed and used in hybrid experimental - numerical procedures of investigation of vibrations of a wing. This paper continues the analysis of time averaged moiré method presented in [1] and develops optical techniques discussed in [2-13].

\section{Experimental measurements of vibrations of a wing}

The developed experimental setup for time averaged projection moiré measurement of vibrations is shown in Fig. 1.

General view of the investigated wing is shown in Fig. 2.

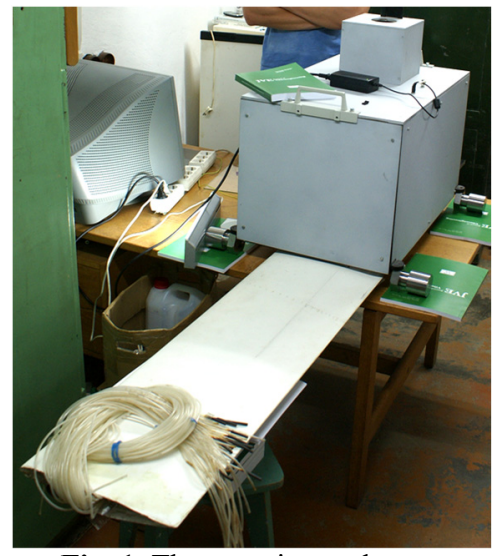

Fig. 1. The experimental setup

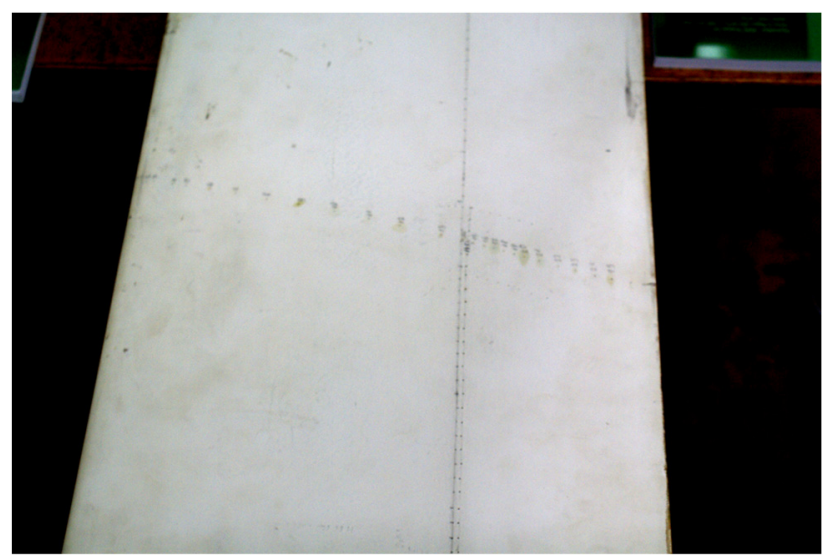

Fig. 2. General view of the investigated wing 
The investigated wing in the experimental setup is shown in Fig. 3.

Experimental images for three different densities of moiré lines are shown in Fig. 4.

The presented images show that it is important to choose acceptable density of moiré lines for measurement of vibrations.

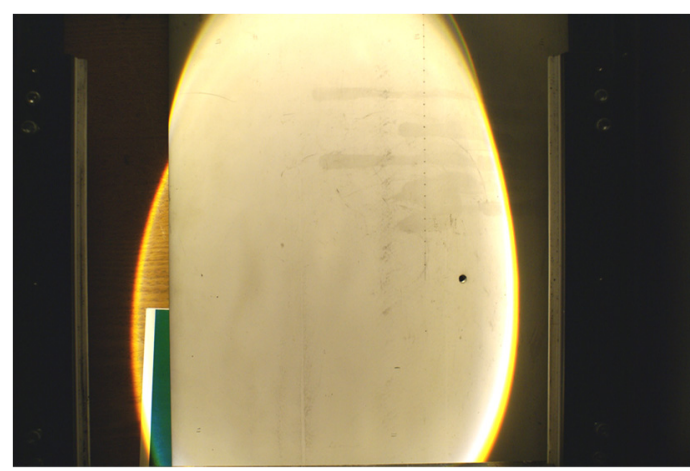

Fig. 3. The investigated wing in the experimental setup

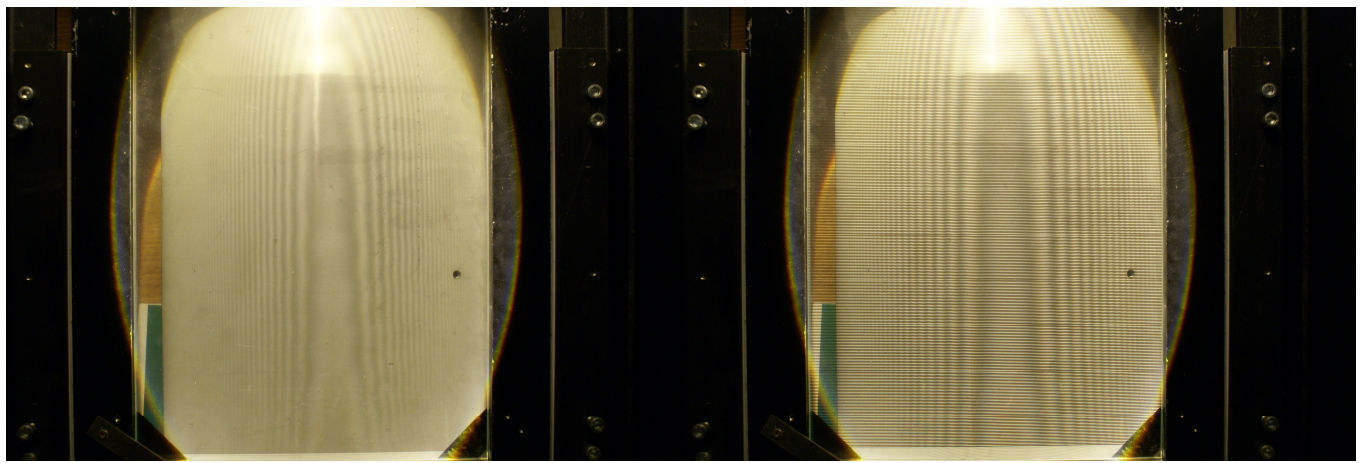

a)

b)

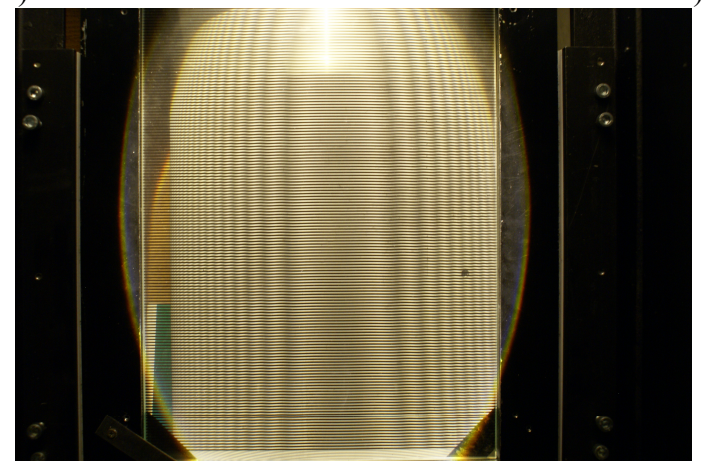

c)

Fig. 4. Experimental images for three different densities of moiré lines

3. Simplified two-dimensional model for the analysis of time averaged projection moiré measurement of vibrations

Intensity of the time averaged projection moiré image is represented as:

$I=\frac{1}{m} \sum_{i=1}^{m} \cos ^{2} \frac{2 \pi}{\lambda}\left(x-\left(d-y-v \sin 2 \pi \frac{i-1}{m}\right) \tan \alpha\right)$, 
where $I$ is the intensity of the time averaged projection moiré image, $m$ is a large integer number, $\lambda$ determines the width of moiré lines, $x$ and $y$ are the coordinates of a point of a structure in the status of equilibrium, $d$ is the distance from the grating to the $x$ axis of coordinates, $v$ is the displacement in the direction of the $y$ axis, $\alpha$ is the angle between the direction of incident light and the $y$ axis.

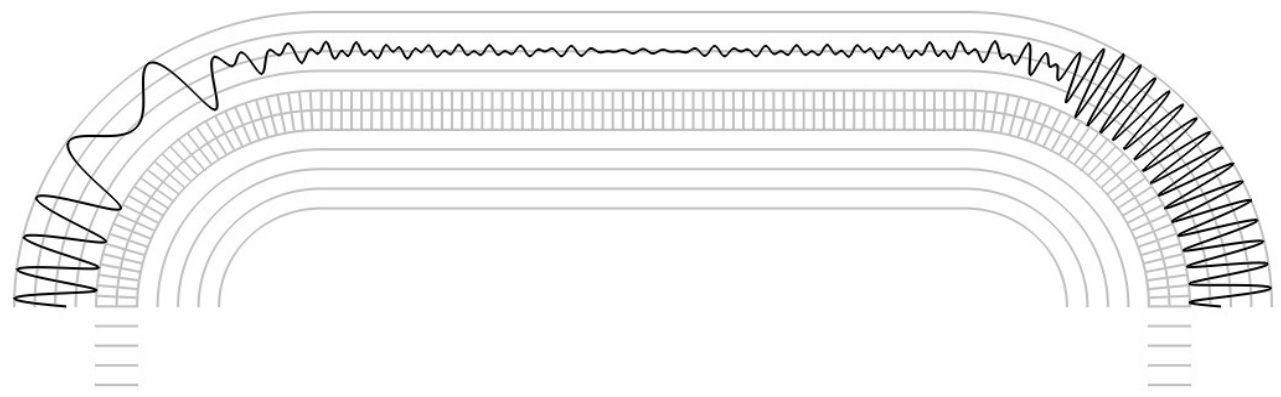

a)

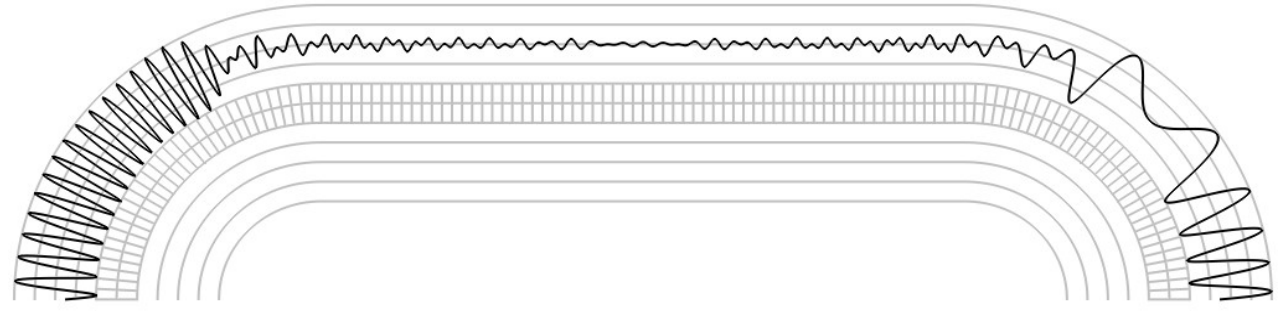

b)

Fig. 5. The first eigenmode when a) $\alpha=-\pi / 4$ and b) $\alpha=\pi / 4$

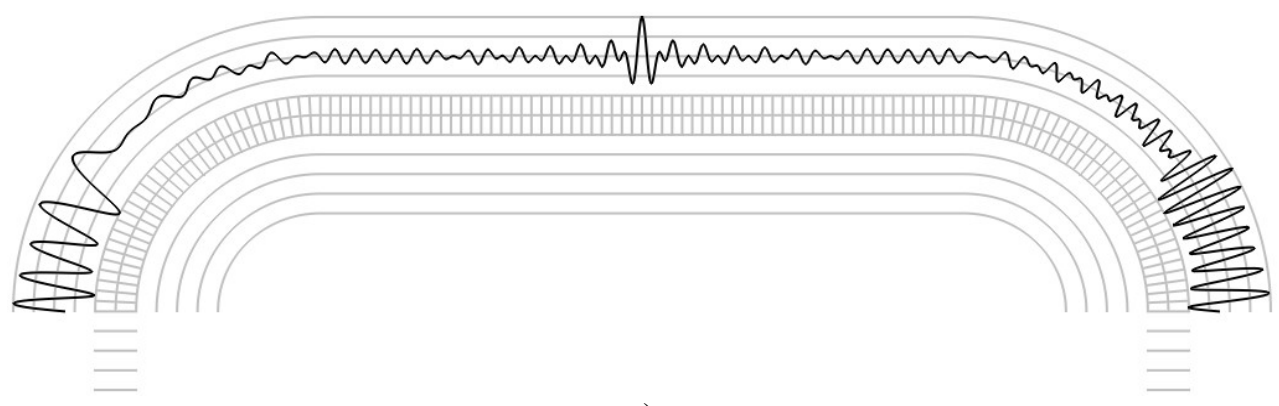

a)

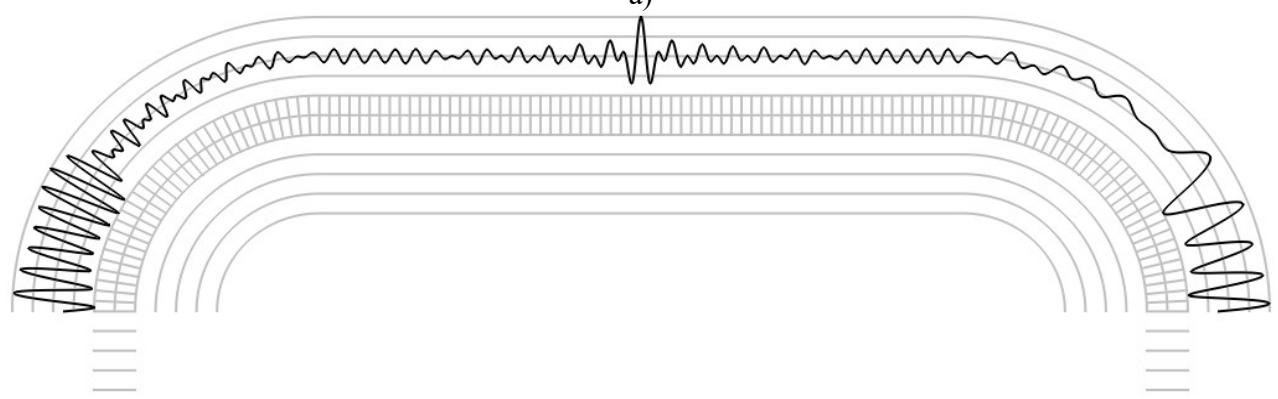

b)

Fig. 6. The second eigenmode when a) $\alpha=-\pi / 4$ and b) $\alpha=\pi / 4$ 
Plane strain problem is investigated. The analyzed structure consists of one row of elements located on one fourth of a circle, of a straight part with the length equal to the length of the middle line of half of a circle and of another one fourth of a circle. The following parameters of the investigated structure are assumed: modulus of elasticity $E=6 \cdot 10^{8} \mathrm{~Pa}$, Poisson's ratio $v=0.3$, density of the material $\rho=785 \mathrm{~kg} / \mathrm{m}^{3}$. All displacements of the three nodes on the left end and of the three nodes on the right end are assumed equal to zero.

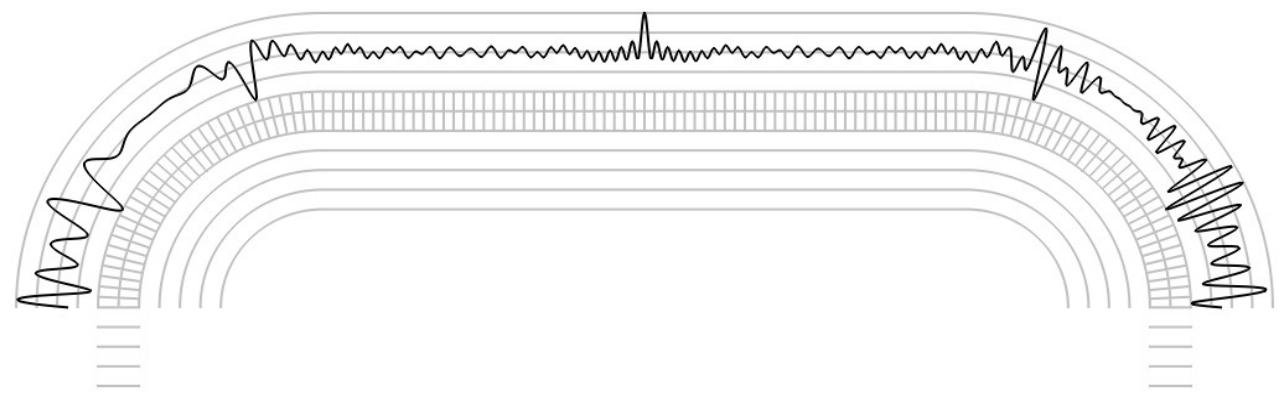

a)

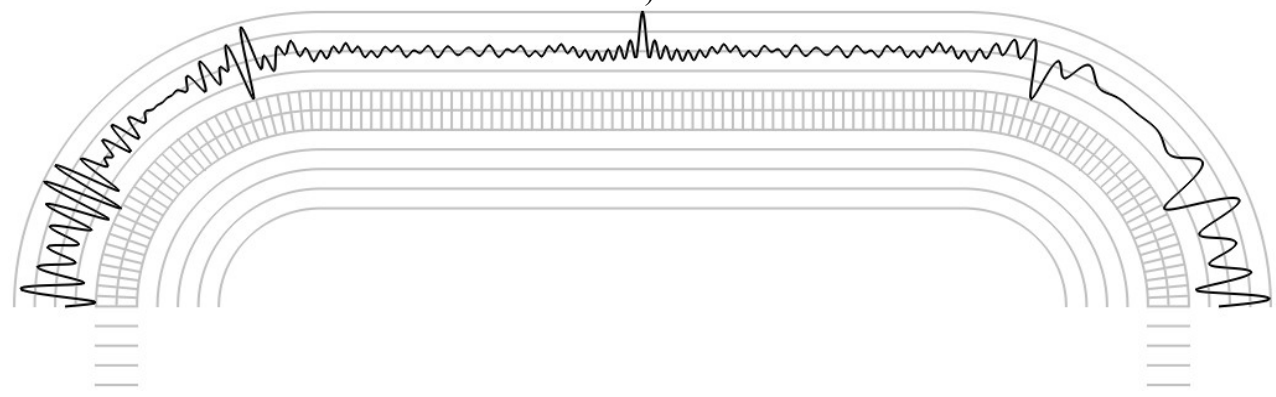

b)

Fig. 7. The third eigenmode when a) $\alpha=-\pi / 4$ and b) $\alpha=\pi / 4$
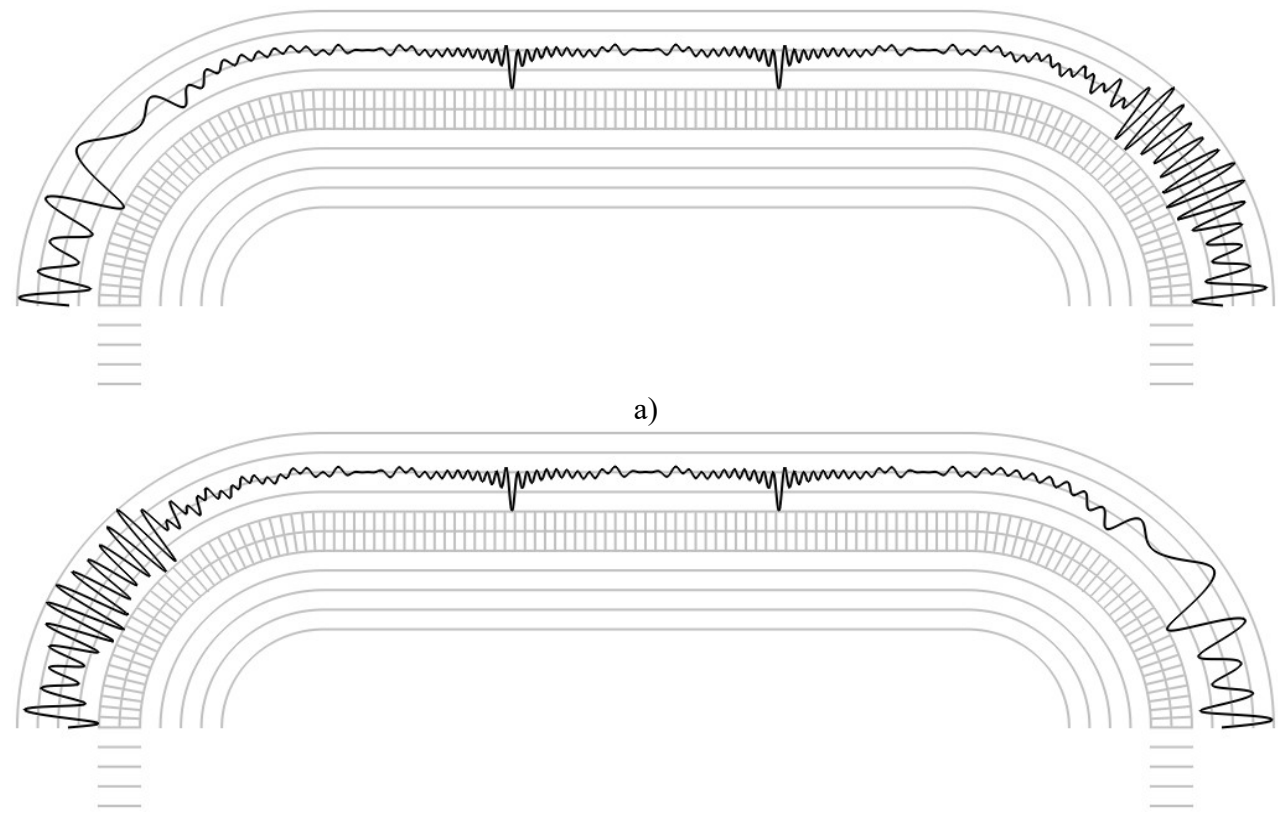

b)

Fig. 8. The fourth eigenmode when a) $\alpha=-\pi / 4$ and b) $\alpha=\pi / 4$ 
The finite element mesh and lines equidistant in the normal direction to the surfaces of the structure are shown in grey color. Intensity of the time averaged projection moiré images on the upper surface is represented graphically in the normal direction to the surface in black colour. Results are presented for $\alpha=-\pi / 4$ and for $\alpha=\pi / 4$. The first eigenmode is shown in Fig. 5, the second eigenmode is shown in Fig. 6, the third eigenmode is shown in Fig. 7 and the fourth eigenmode is shown in Fig. 8.

Graphical relationships of this type are used in hybrid experimental - numerical procedures for interpretation of time averaged projection moiré images on shallow surfaces of wing type. For such surfaces with slow variation of curvature graphical representations of this type are to be investigated for a number of cross sections of the analyzed structure.

\section{Conclusions}

Vibrations of a wing are investigated experimentally by using the method of time averaged projection moiré. Experimental setup is developed and the results obtained by using the experimental procedure are analyzed.

For interpretation of projection moiré images on a shallow surface a special simplified two-dimensional numerical model is developed and used in hybrid experimental - numerical procedures of investigation of vibrations of a wing. For such surfaces with slow variation of curvature graphical representations of the described type are to be investigated for a number of cross sections of the analyzed structure.

\section{References}

[1] Ragulskis K., Maskeliūnas R., Zubavičius L. Analysis of structural vibrations using time averaged shadow moiré. Journal of Vibroengineering, Vol. 8, Issue 3, 2006, p. 26-29.

[2] Ragulskis M., Maskeliūnas R., Ragulskis L., Turla V. Investigation of dynamic displacements of lithographic press rubber roller by time average geometric moiré. Optics and Lasers in Engineering, Vol. 43, 2005, p. 951-962.

[3] Ragulskis M., Maskeliūnas R., Ragulskis L. Plotting moiré fringes for circular structures from FEM results. Experimental Techniques, Vol. 26, Issue 1, 2002, p. 31-35.

[4] Huimin X., Guotao W., Fulong D., Guangjun Z., Xingfu L., Fangju Z., Aiming X. The dynamic deformation measurement of the high speed heated LY12 aluminium plate with moiré interferometry. Journal of Materials Processing Technology, Vol. 83, Issues 1-3, 1998, p. 159-163.

[5] Deason V. A., Epstein J. S., Abdallah A. Dynamic diffraction moiré: theory and applications. Optics and Lasers in Engineering, Vol. 12, Issues 2-3, 1990, p. 173-187.

[6] Kokaly M. T., Lee J., Kobayashi A. S. Moiré interferometry for dynamic fracture study. Optics and Lasers in Engineering, Vol. 40, Issue 4, 2003, p. 231-247.

[7] Timoshenko S. P., Goodier J. N. Theory of Elasticity. Nauka, Moscow, 1975.

[8] Soifer V. A. Computer processing of images. Herald of the Russian Academy of Sciences, Vol. 71, Issue 2, 2001, p. 119-129.

[9] Vest C. Holographic Interferometry. Mir, Moscow, 1982.

[10] Han B., Post D., Ifju P. Moiré interferometry for engineering mechanics: current practices and future developments. Journal of Strain Analysis for Engineering Design, Vol. 36, Issue 1, 2001, p. 101-117.

[11] Field J. E., Walley S. M., Proud W. G., Goldrein H. T., Siviour C. R. Review of experimental techniques for high rate deformation and shock studies. International Journal of Impact Engineering, Vol. 30, Issue 7, 2004, p. 725-775.

[12] Dai F. L., Wang Z. Y. Geometric micron moiré. Optics and Lasers in Engineering, Vol. 31, Issue 3, 1999, p. 191-198.

[13] Liang C. Y., Hung Y. Y., Durelli A. J., Hovanesian J. D. Time-averaged moiré method for in-plane vibration analysis. Journal of Sound and Vibration, Vol. 62, Issue 2, 1979, p. 267-275. 